\title{
Manifestation features of near-surface sedimentary rock electric and acoustic responses on seismic waves from earthquakes
}

\author{
Pavel Muratov ${ }^{1, *}$, Oleg Rulenko ${ }^{2}$, and Yuriy Marapulets ${ }^{1}$ \\ ${ }^{1}$ Institute of Cosmophysical Research and Radio Wave Propagation FEB RAS, Mirnaya, 7, Paratunka, \\ Kamchatkskiy kray, 684034, Russia \\ ${ }^{2}$ Institute of Volcanology and Seismology FEB RAS, bul'var Piypa, 9, Petropavlovsk-Kamchatskiy, \\ 683006, Russia
}

\begin{abstract}
The results of analysis of near-surface sedimentary rock electric and acoustic responses on seismic waves from five Kamchatka earthquakes with the magnitudes of $4.9-7.3$ at the distances of $79-498 \mathrm{~km}$ from epicenters are presented. Manifestation features of these responses, depending upon earthquake magnitude, epicentral distance, source depth and direction to an epicenter, are considered.
\end{abstract}

\section{Introduction}

Propagation of seismic waves from earthquakes is accompanied by deformation of nearsurface rocks among which sedimentary rocks are widely distributed. About $80 \%$ of continent surfaces are covered by them [1]. Sedimentary rocks are a complexly-constructed polydisperse water- and gas-saturated porous medium of low strength and, thus, are easily deformed. Under the seismic wave effect, stress-strain state change is accompanied by wave mechanic energy into the energies of other physical fields. Among these transformations, seismoelectric effect of the second kind is well known. It was discovered on sedimentary complex rocks by Ivanov A.G. [2]. The effect consists in generation of electric field during fluid phase sift relatively rock solid fragments and distortion of equilibrium state in the double electric layer which exits at the boundary of the fragment and the fluid. During the deformations by seismic waves, relative micro-shifts of rock fragments also take place as well as surface interactions which are accompanied by acoustic signal generation in the frequency range from seismic waves to the first tens of $\mathrm{kHz}$. Seismoacoustic effect at the frequencies from the first hundreds of $\mathrm{Hz}$ to the first tens of $\mathrm{kHz}$ was discovered in Kamchatka [3].

In the paper [4] joint electric and acoustic responses of the near-surface sedimentary rocks on the passage of seismic waves from earthquakes was detected for the first time. It indicates simultaneous transformation of wave energy into the energy of electric and acoustic fields. This response is the earthquake co-seismic effect, and rocks may be considered as simultaneously operating electric and acoustic seismographs. It occurs in the result of collective reaction of closely-packed sedimentary rock fragments, having a wide range of sizes, on elastic deformation.

\footnotetext{
*e-mail: pavel_mure@yandex.ru
} 
Joint investigation of seismoelectric and seismoacoustic effects, different in genesis but having common deformation nature, characterizes sedimentary rock deformations better. The obtained results may be applied to investigate electrophysical and mechanical properties as well as joint disturbances of high-frequency geoacoustic emission and atmospheric electric field occurring during tectonoseismic deformation [5]. Seismic waves affect sedimentary rocks which are under mechanical stress. Thus, the intensity of wave mechanical energy transformation into electric and acoustic field energy is much determined not only by rock structure and texture but their stress-deformed state as well $[6,7]$. Taking this into account, seismoelectric and seismoacoustic signal monitoring may be of current interest to trace the near-surface sedimentary rock stress state at an observation site.

\section{Observation method and data analysis}

Observations of seismoelectric and seismoacoustic effect were carried out at "Karymshina" site $\left(52.83^{\circ} \mathrm{N}, 158.13^{\circ} \mathrm{E}\right)$ of the Institute of Cosmophysical Research and Radio Wave Propagation FEB RAS. This site is located in the region of Verchne-Paratunskaya hydrothermal system of southern Kamchatka (figure 1). Electric field horizontal components were recorded by two orthogonal slotted lines of the length of $10 \mathrm{~m}$ oriented along the magnetic meridian $(\mathrm{N}-\mathrm{S})$ and perpendicularly to it $(\mathrm{E}-\mathrm{W})$. Buried into the ground at a depth of $1.0 \mathrm{~m}$, lead plates with the dimensions of $0.25 \times 1.0 \mathrm{~m}^{2}$ were used as electrodes. $\mathrm{N}-\mathrm{S}$ line interelectrode resistance was $10.5 \mathrm{k} \Omega$, and that of $\mathrm{E}-\mathrm{W}$ line was $8.7 \mathrm{k} \Omega$. Potential difference between the electrodes was applied to a pre-amplifier with input resistance of $1 \mathrm{M} \Omega$. The device was located near the slotted lines.

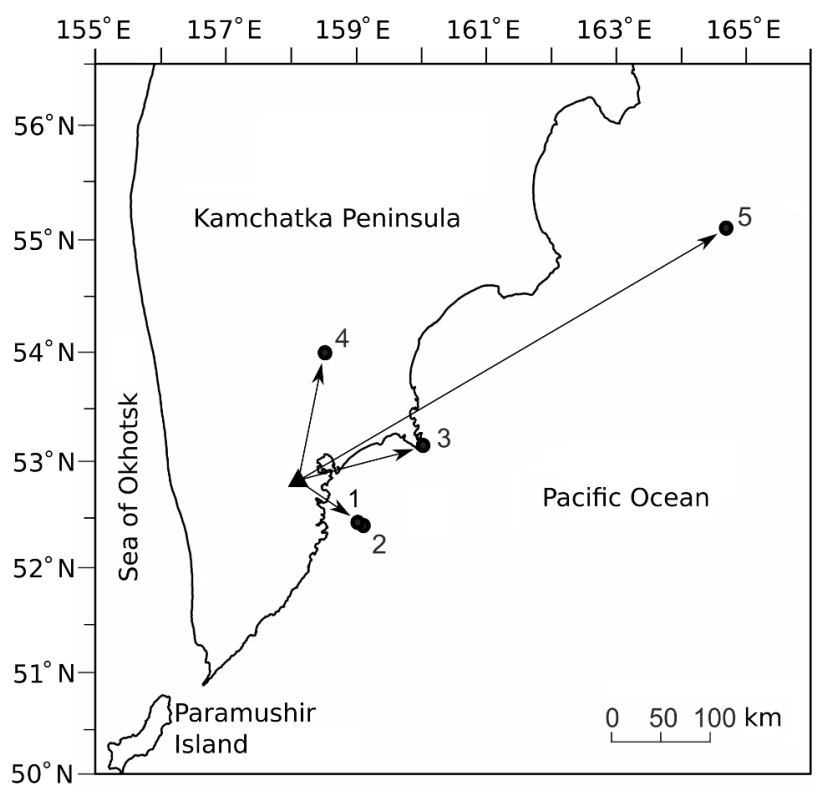

Figure 1. Location of "Karymshina" site $(\mathbf{\Lambda})$ and earthquake epicenters $(\bullet)$ for which seismoelectric and seismoacoustic signals were analyzed. Earthquake parameters are in the Table. Arrows indicate the directions to epicenters, magnetic azimuths are the arrow azimuth 
A broad-band piezoceramic hydrophone, having the sensitivity of about $1 \mathrm{~V} / \mathrm{Pa}$ together with the pre-amplifier, was used as an acoustic signal receiver. It was suspended in an artificial water pool of the size of $1 \times 1 \times 1 \mathrm{~m}^{3}$ at the depth of $0.5 \mathrm{~m}$. The hydrophone directional diagram was $60^{\circ}$, it was oriented vertically downwards and was placed at the point of intersection of slotted lines for the electric field.

The electric and acoustic signals were digitized by a general 8-channel 16-bit professional sound card M-Audio Fast Track Ultra 8R with the sampling frequency of $48 \mathrm{kHz}$ that provided synchronous recording of electric and acoustic data. The recorded frequency range of all the signals was $0.1 \mathrm{~Hz}-11 \mathrm{kHz}$.

According to the results of drilling, the near-surface rocks at "Karymshina" site are sedimentary with the layer thickness of about $50 \mathrm{~m}$ [8]. There is a well No. 99-8 with the depth of $19 \mathrm{~m}$ located $170 \mathrm{~m}$ away from the hydrophone. Its lithologic log is presented by boulderpebble deposits with sand and clay filler $(0-5 \mathrm{~m})$, block and gravel deposits with clay filler $(5-14 \mathrm{~m})$ and boulder-pebble deposits with sand filler $(14-19 \mathrm{~m})$. Based on the estimates made in the paper [3], the sources of acoustic signals, occurring at the frequencies from the first hundreds of $\mathrm{Hz}$ to the first tens of $\mathrm{kHz}$, are located at a distance up to the first tens of meters from the hydrophone. Taking all this into account and the distance between the electrodes and their depth in the ground, we can assume that seismoelectric and seismoacoustic signals were generated in the near-surface sedimentary rocks.

Formation of the seismoelectric and seismoacoustic response of sedimentary rocks will occur as follows. Electric field disturbances will appear at seismic wave mechanic effect frequencies. When applying such a hydrophone setup, $P$-wave pattern will be recorded without significant distortions since the refraction may be neglected if the water pool is so small. Water does not have form elasticity and $S$-wave pattern will not propagate in a pool, however, causing horizontal and vertical ground shifts, it will affect the hydrophone via a string and appear in the obtained data [3]. Thus, we considered only acoustic signals occurring only during $P$-wave passage. These signal frequencies will be determined by the sizes of rock fractions interacting at a given moment that is determined by the dynamics of their deformation by seismic waves.

Table 1. Parameters of the earthquakes for which seismoelectric and seismoacoustic signals were analyzed, distance to an earthquake epicenter $R$ and magnetic azimuth to an epicenter $A$

\begin{tabular}{|c|c|c|c|c|c|c|c|c|c|}
\hline \multirow{2}{*}{ No. } & \multicolumn{2}{|c|}{ Earthquake } & \multicolumn{2}{|c|}{$\begin{array}{c}\text { Epicenter } \\
\text { coordinates }\end{array}$} & \multirow{2}{*}{$\begin{array}{c}\text { Depth, } \\
\mathrm{km}\end{array}$} & $K_{s}$ & $\begin{array}{c}\text { Magni- } \\
\text { tude }\end{array}$ & $\begin{array}{c}\mathrm{R}, \\
\mathrm{km}\end{array}$ & $A^{\circ}$ \\
\cline { 2 - 12 } & $\begin{array}{c}\text { Date, } \\
\text { UTC }\end{array}$ & $\begin{array}{c}\text { Time, } \\
\text { UTC }\end{array}$ & Lat. $^{\circ} \mathrm{N}$ & Long..$^{\circ} \mathrm{E}$ & & & & & \\
\hline 1 & $08-02-2019$ & $17: 08: 35$ & 52.42 & 159.05 & 59 & 12.0 & $5.3 M_{l}$ & 76 & 131.9 \\
\hline 2 & $14-02-2019$ & $18: 24: 27$ & 52.39 & 159.13 & 58 & 11.2 & $4.9 M_{l}$ & 82 & 131.6 \\
\hline 3 & $03-01-2019$ & $17: 57: 43$ & 53.14 & 160.05 & 58 & 12.2 & $5.4 M_{l}$ & 133 & 80 \\
\hline 4 & $30-01-2016$ & $03: 25: 12$ & 53.978 & 158.546 & 177.0 & & $7.2 \mathrm{mww}$ & 131 & 18 \\
\hline 5 & $20-12-2018$ & $17: 01: 55$ & 55.100 & 164.699 & 16.6 & & $7.3 \mathrm{mww}$ & 498 & 66 \\
\hline
\end{tabular}

The table 1 presents earthquake parameters during which seismoelectric and seismoacoustic signals were analyzed. The parameters of weaker earthquakes No. 1 3 were taken from the Catalogue of Kamchatka Branch of FIC ECS RAS (http://sdis.emsd.ru/info/earthquakes/catalogue.php). Their energy classes $K_{s}$ and local magnitudes $M_{l}$ are shown. The parameters of stronger seismic events No. 4, 5 were taken from NEIC Catalogue (https://earthquake.usgs.gov/earthquakes/search/). In all the cases the distance from "Karymshina" site to an earthquake epicenter $R$ and magnetic azimuth to an epi- 
center $A$ were presented. The epicenter locations with the numbers, illustrated in the table 1 , are shown in figure 1.

The electric and acoustic signals, recorded during seismic wave passage, were considered in different frequency ranges and their spectrograms were calculated. The analysis results are illustrated in figures $2-5$. They contain the earthquake occurrences times and $P$ - and $S$-waves onsets from it at "Karymshina" site of Kamchatka Branch of FIC ECS RAS which is located $250 \mathrm{~m}$ from our observation site.

\section{Results and discussion}
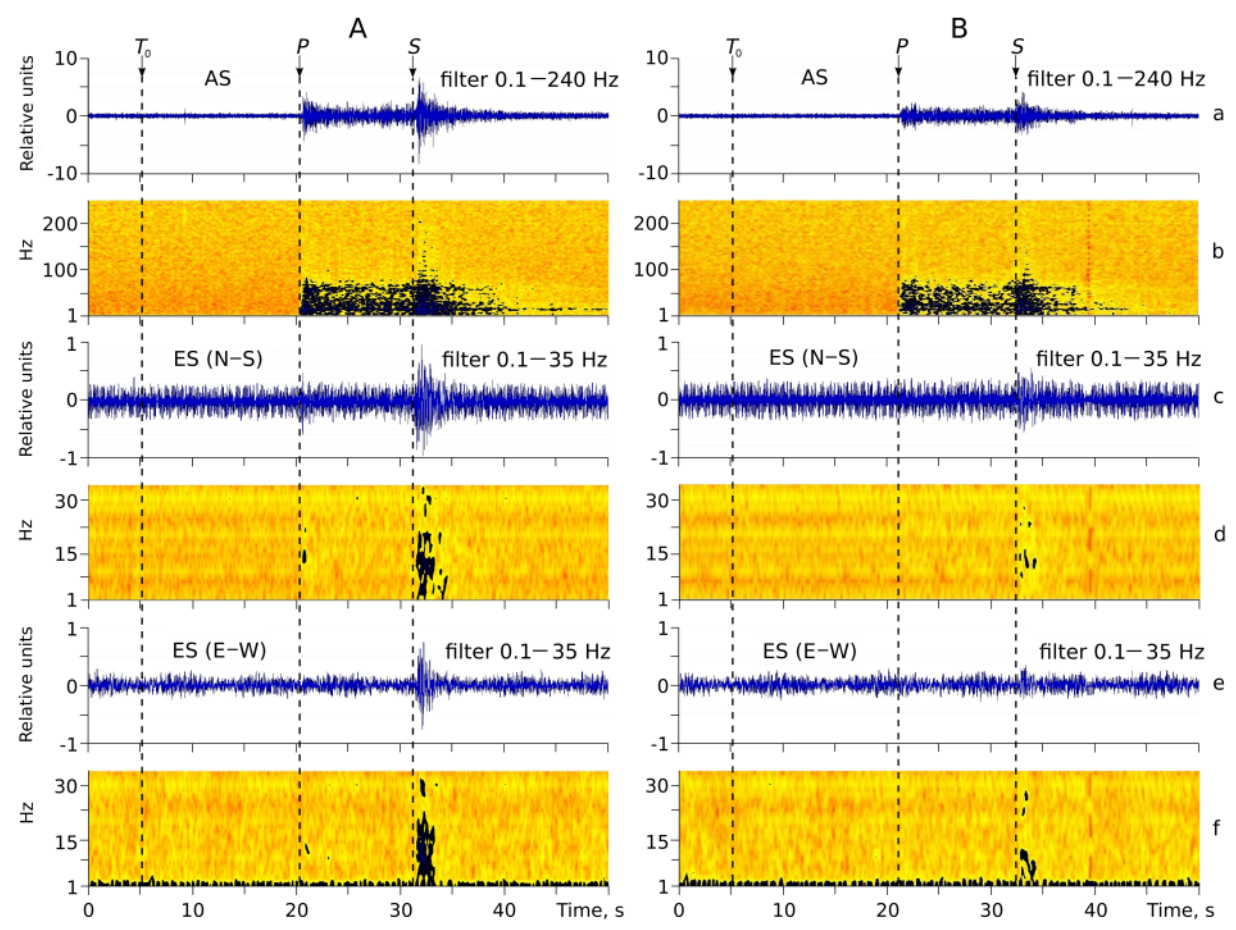

Figure 2. Analysis results for acoustic and electric signals recorded during seismic wave passage from earthquake No. 1 (figure 1, table 1) - A and No. 2 (figure 1, table 1) - B. Arrows indicate earthquake occurrence times $T_{0}$ and $P$ - and $S$-wave onsets. $A S$ - acoustic signal, $E S$ - electric signal; a, c, e signal records; $\mathrm{b}, \mathrm{d}, \mathrm{f}$ - their spectrograms, respectively

Earthquakes No. 1, 2 (figure 1, table 1). Figure 2 illustrates the analysis results for acoustic and electric signals recorded during the passage of seismic waves from two close earthquakes. Earthquake No. 2 occurred 6 days after earthquake No. 1 and was caused by rock seismogenic volume which was located near the source region of earthquake No. 1. These paired earthquakes are of interest since as sources of seismoacoustic and seismoelectric signals, they have common spatial location of sources but are differ in energy. Considering them, we can definitely speak on the dependence of acoustic and electric responses of sedimentary rocks on earthquake energy. Moreover, mechanic and electrophysical properties of 
these rocks as well as seismoacoustic and seismoelectric transformation characteristics could not change significantly within such a small time interval at the observation site.

Earthquake No. 1 was 6 times as much in energy as earthquake No. 2, and as it is clear from figure 2 , the both responses of sedimentary rocks during earthquake No. 1 were stronger. During both earthquakes, the acoustic response on $P$-wave was less than $60 \mathrm{~Hz}$ and the electric response was much weaker than on $S$-wave. Electric response intensities at $\mathrm{N}-\mathrm{S}$ and $\mathrm{E}-\mathrm{W}$ channels were almost similar but during earthquake No. 2 they were significantly weaker. It may be explained by similar magnetic azimuths, that means similar directions to earthquake epicenters (figure 1, table 1). Electric signal highest intensity during the $S$-wave passage was $35 \mathrm{~Hz}$.

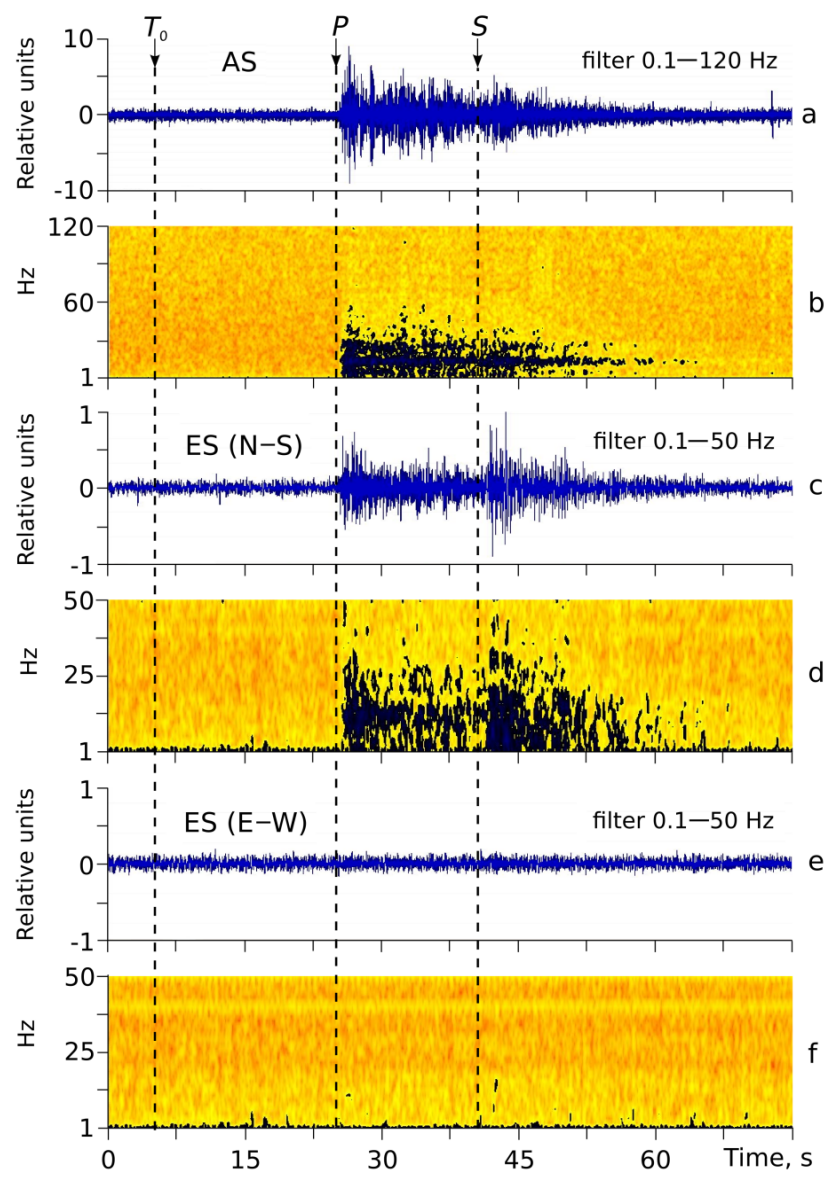

Figure 3. Analysis results for acoustic and electric signals recorded during seismic wave passage from earthquake No. 3 (figure 1, table 1). AS - acoustic signal, ES - electric signal; a,c,e - signal records; b,d,f - their spectrograms, respectively. Arrow symbols are the same as in figure 2

Earthquake No. 3 (figure 1, table 1). The analysis results for seismoacoustic and seismoelectric signals recorded during the earthquake are illustrated in figure 3. Just like for earthquakes No. 1 and 2, the sedimentary rock response on $P$-wave was less than $60 \mathrm{~Hz}$. The electric response had strong anisotropy that meas the presence of intensive signal in $\mathrm{N}-\mathrm{S}$ 
channel and almost its total absence in $\mathrm{E}-\mathrm{W}$ channel (figure 3c-f). In $\mathrm{N}-\mathrm{S}$ channel, a signal close in intensity was observed during the passages of both types of seismic waves and its highest intensity reached $50 \mathrm{~Hz}$.

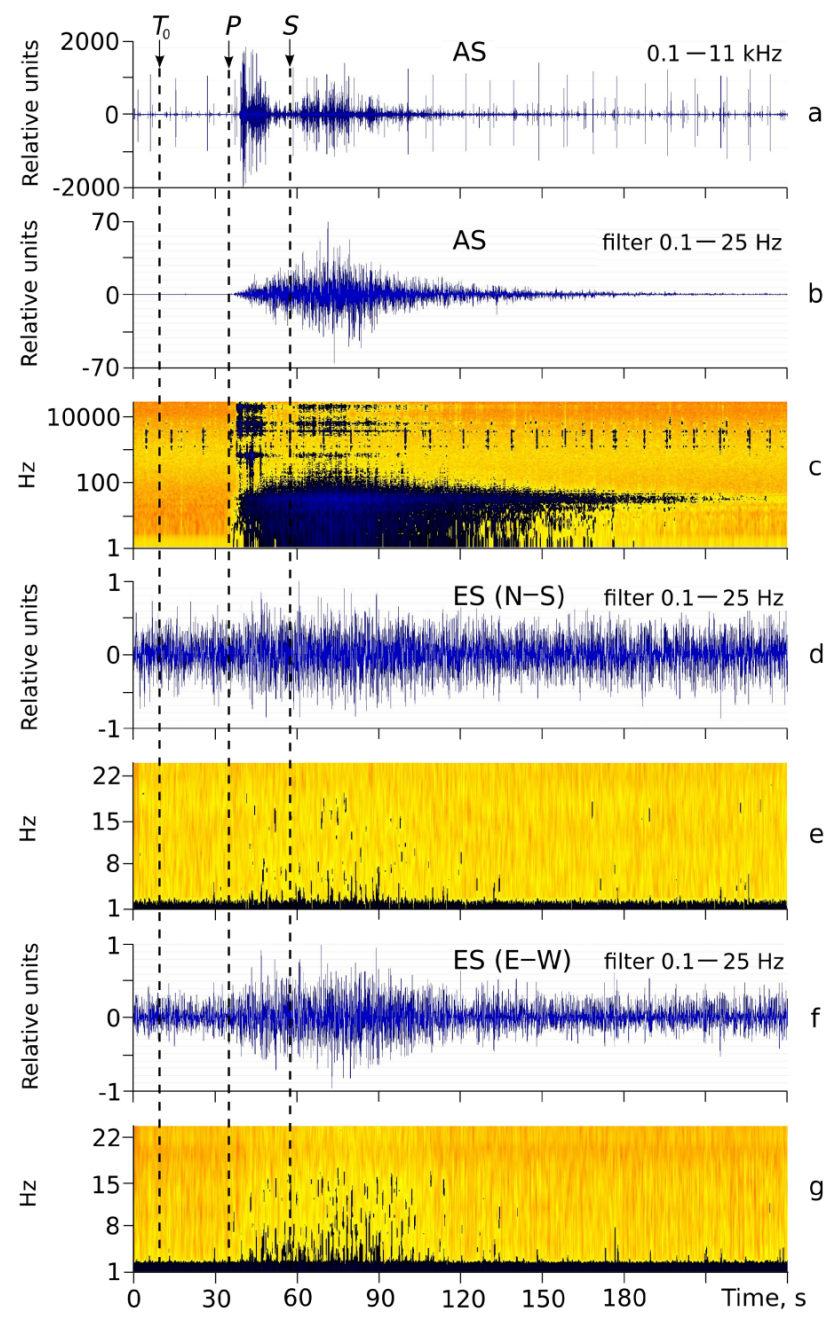

Figure 4. Analysis results for acoustic and electric signals recorded during seismic wave passage from earthquake No. 4 (figure 1, table 1). AS - acoustic signal, $E S$ - electric signal; a, b, d, f - signal records; c, e, $\mathrm{g}$ - their spectrograms, respectively. Arrow symbols are the same as in figure 2

Earthquakes No. 4, 5 (figure 1, table 1). Earthquakes No. 1 - 3 are moderate-energy local earthquakes with similar depths of sources. To investigate seismoacoustic and seismoelectric responses of sedimentary rocks, it is important to know these responses during strong earthquakes. As such we considered seismic events No. 4 and 5 which have almost similar magnitudes but different depths of sources and distances to epicenters.

Figure 4 shows the analysis results for seismoacoustic and seismoelectric signals recorded during earthquake No. 4. It is clear on the spectrogram of the acoustic signal (figure 4c) that acoustic energy was released in three frequency clusters during the $P$-wave passage. Be- 
sides the low-frequency cluster of about $100 \mathrm{~Hz}$, there were two clusters at the frequencies of about $0.1-1$ and $1-11 \mathrm{kHz}$. They indicate transformation of seismic wave low-frequency energy into significantly higher-frequency energy of acoustic signals. Such transformation evidently occurs during the interaction of sedimentary rock smallest fractions. As it is clear on the electric signal spectrograms (figure $4 \mathrm{e}, \mathrm{g}$ ), the electric energy was released at the frequencies up to $15-20 \mathrm{~Hz}$ and the release intensity was higher in $\mathrm{E}-\mathrm{W}$ channel. We should note that during the $P$ - and $S$-wave passages from this earthquake, the electric signals were also recorded $250 \mathrm{~m}$ from our site at the depth of $1.3 \mathrm{~m}$ in the ground [9].

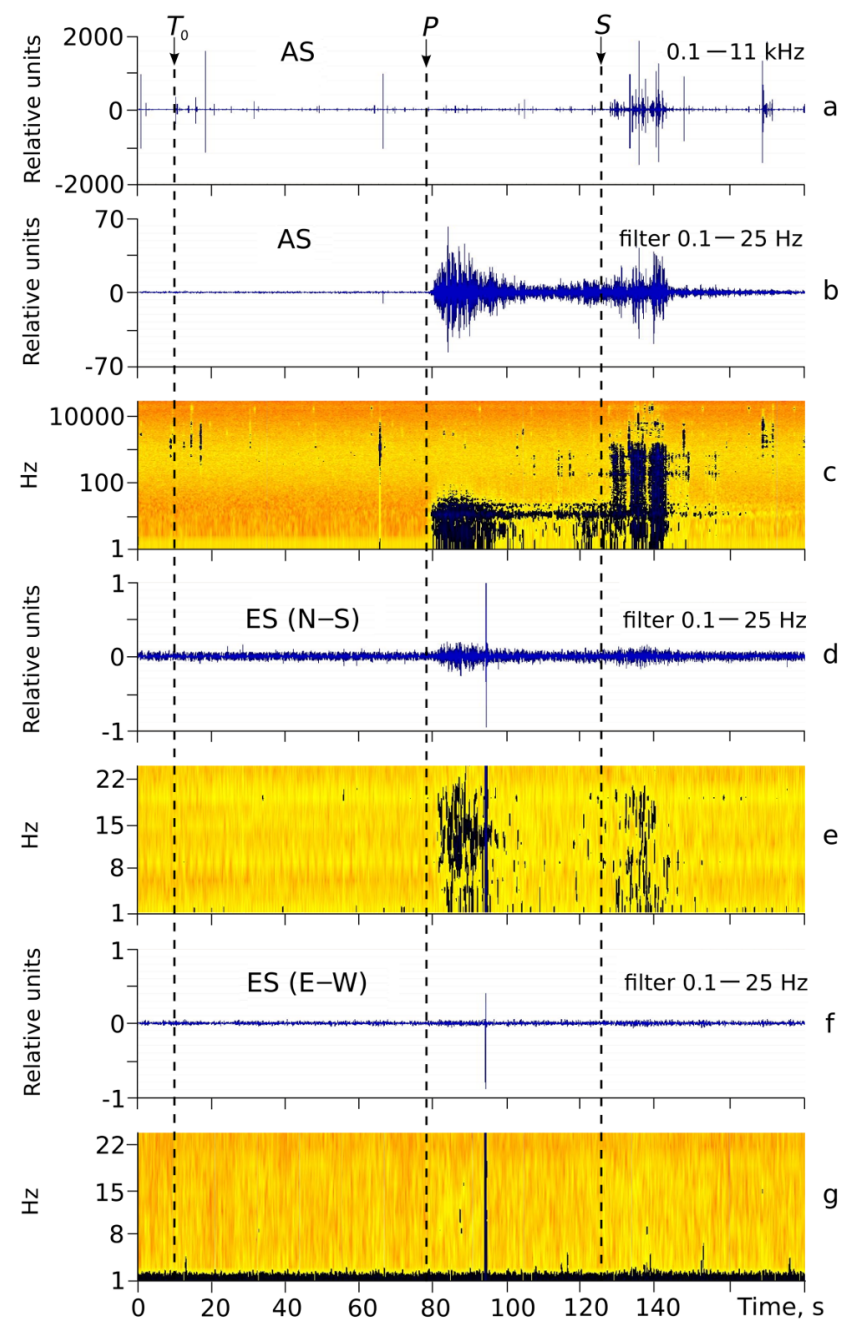

Figure 5. Analysis results for acoustic and electric signals recorded during seismic wave passage from earthquake No. 5 (figure 1, table 1). AS — acoustic signal, $E S$ - electric signal; a, b, d, f — signal records; c, e, g — their spectrograms, respectively. Arrow symbols are the same as in figure 2

Figure 5 illustrates the analysis results for acoustic and electric signals recorded during seismic wave passage from earthquake No. 5. In contrast to earthquake No. 4, there are 
no kilohertz acoustic clusters during the $P$-wave passage (figure 5c). The energy released during these earthquakes in the form of seismic waves is almost similar and the absence of such clusters may be explained by earthquake No. 5 small depth and large distance to the epicenter. The electric response has the same anisotropy as for earthquake No. 3. It consists in the presence of a significant signal in $\mathrm{N}-\mathrm{S}$ channel and almost its total absence in $\mathrm{E}-\mathrm{W}$ channel (figure $5 \mathrm{~d}-\mathrm{g}$ ). It is likely to be associated with close directions to the epicenters of earthquakes No. 5, 3 relatively the slotted lines for the electric field. The electric response during earthquake No. 5 was up to $20-22 \mathrm{~Hz}$. Strong electric signal at the time instant of $\approx 94 \mathrm{~s}$ (figure $5 \mathrm{~d}-\mathrm{g}$ ) was caused by a group of strong atmospherics according to the data of electromagnetic observations at "Karymshina" site.

\section{Conclusions}

We have found the following manifestation features of near-surface sedimentary rock electric and acoustic responses on seismic waves from the earthquakes under considerations:

1. During two moderate close earthquakes No. 1, 2 with spatial location of sources but different energy, the dependence of response manifestation intensity on earthquake energy was discovered.

2. During strong remote earthquake No. 5 and moderate local earthquake No. 3 with close directions to epicenters, there is a similar anisotropy of the electric response. It consists in the presence of a significant signal in $\mathrm{N}-\mathrm{S}$ channel and almost its total absence in $\mathrm{E}-$ W channel. During earthquakes No. 1, 2 with similar directions to epicenters, the electric response intensity in $\mathrm{N}-\mathrm{S}$ and $\mathrm{E}-\mathrm{W}$ channels is similar in spite of the different energy of earthquakes.

3. During strong seismic events No. 4 and 5, having close energy of the emitted seismic waves, there is a significant difference of sedimentary rock acoustic response on $\mathrm{P}$ - wave. It consists in the presence of kilohertz clusters during relatively close and deep earthquake No. 4 and their absence during the remote shallow earthquake No. 5.

\section{References}

[1] R.M. Garrels, F.T. Mackenzie, Evolution of sedimentary rocks (W.W. Norton and Company, Inc., New York, 1971) 397

[2] A.G. Ivanov, Proceedings of the Academy of Sciences of the USSR, a series of geographical and geophysical, 5, 18-21 (1940)

[3] Yu.V. Marapulets, B.M. Shevtsov, Mesoscale acoustic emission (Vladivostok, Dal'nauka, 2012) 126

[4] P.V. Muratov, O.P. Rulenko, Yu.V. Marapulets, A.A. Solodchuk, Bulletin KRASEC. Physical \& Mathematical Sciences, 5(25), 62-73 (2018)

[5] Y. Marapulets, O. Rulenko, Atmosphere 10(5), $267 \quad$ (2019) https://doi.org/10.3390/atmos10050267

[6] N.I. Migunov, Izvestiya. Physics of the Solid Earth 9, 20-28 (1984)

[7] Yu.V. Marapulets, B.M. Shevtsov, I.A. Larionov, et al., Geology of the Pacific Ocean 31(6), 59-67 (2012)

[8] A.V. Kuptsov, I.A. Larionov, B.M. Shevtsov, Volcanology and Seismology 5, 45-59 (2005)

[9] V.A. Kasimova, M.E. Potanin, N.Yu. Berseneva, Proceedings of VII International Conference «Solar-Terrestrial Relations and Physics of Earthquake Precursors». Petropavlovsk-Kamchatksiy, IKIR DVO RAN, 308-312 (2016) 